\title{
Contribution of large-scale midlatitude disturbances to hourly precipitation extremes in the United States
}

\author{
Renaud Barbero ${ }^{1,2}$. John T. Abatzoglou ${ }^{3} \cdot$ Hayley J. Fowler ${ }^{1}$
}

Received: 14 October 2017 / Accepted: 2 February 2018 / Published online: 27 February 2018

(c) The Author(s) 2018. This article is an open access publication

\begin{abstract}
Midlatitude synoptic weather regimes account for a substantial portion of annual precipitation accumulation as well as multiday precipitation extremes across parts of the United States (US). However, little attention has been devoted to understanding how synoptic-scale patterns contribute to hourly precipitation extremes. A majority of 1-h annual maximum precipitation (AMP) across the western US were found to be linked to two coherent midlatitude synoptic patterns: disturbances propagating along the jet stream, and cutoff upper-level lows. The influence of these two patterns on 1-h AMP varies geographically. Over 95\% of 1-h AMP along the western coastal US were coincident with progressive midlatitude waves embedded within the jet stream, while over 30\% of 1-h AMP across the interior western US were coincident with cutoff lows. Between 30-60\% of 1-h AMP were coincident with the jet stream across the Ohio River Valley and southeastern US, whereas a majority of 1-h AMP over the rest of central and eastern US were not found to be associated with either midlatitude synoptic features. Composite analyses for 1-h AMP days coincident to cutoff lows and jet stream show that an anomalous moisture flux and upper-level dynamics are responsible for initiating instability and setting up an environment conducive to 1-h AMP events. While hourly precipitation extremes are generally thought to be purely convective in nature, this study shows that large-scale dynamics and baroclinic disturbances may also contribute to precipitation extremes on sub-daily timescales.
\end{abstract}

Keywords Hourly precipitation extremes $\cdot$ Synoptic patterns $\cdot$ Jet stream $\cdot$ Cutoff lows $\cdot$ United-States

\section{Introduction}

Hourly precipitation extremes have received much attention due to the hazards they pose to human lives and infrastructure (Ashley and Ashley 2008; Terti et al. 2017). Widespread increases in the magnitude of hourly precipitation extremes have been documented in the United States (US) over the past half-century (Barbero et al. 2017) and climate projections suggest a continued intensification of short-duration precipitation extremes with anthropogenic climate change (Prein et al. 2016; Zhang et al. 2017). While changes in precipitation extremes may arise in a changing climate due

Renaud Barbero

renaud.barbero@irstea.fr

1 School of Engineering, Newcastle University, Newcastle-upon-Tyne, UK

2 Irstea, Mediterranean Ecosystems and Risks, Aix-en-Provence, France

3 Department of Geography, University of Idaho, Moscow, Idaho, USA to thermodynamic processes (Pall et al. 2007), understanding the meso-to-synoptic scale dynamics that initiate precipitation extremes under present day climate remains an important research question and is critical to resolving future changes in precipitation extremes (Pfahl et al. 2017).

Precipitation in midlatitudes is often associated with synoptic patterns that initiate and maintain anomalous lower tropospheric moisture convergence and uplift (Zhao et al. 2016). Large-scale midlatitude frontal systems generally cover a large geographic area over a long-duration, that depends on both the mean zonal wind and the zonal length of storms (Dwyer and O'Gorman 2017), with an average storm duration of 30-50 h (Lamjiri et al. 2017). By contrast, shorter-duration precipitation extremes are thought to be geographically localized and associated with deep convection or mesoscale convective systems [e.g., (Schumacher and Johnson 2006; Prein et al. 2017)]. The relative contribution of large-scale midlatitude disturbances vs smaller-scale organized convection to precipitation extremes likely varies geographically and seasonally. Recent findings show that large-scale midlatitude synoptic patterns can also contribute 
considerably to precipitation extremes on sub-daily timescales (Utsumi et al. 2017). Indeed, meso-scale convective processes responsible for heavy precipitation rates are often connected with large-scale vertical velocity and moisture convergence (Lenderink et al. 2017) associated with synoptic-scale patterns (Loriaux et al. 2017). Previous studies have shown that daily or multi-day precipitation extremes in the US are often coincident with atmospheric rivers [e.g., (Dettinger et al. 2011; Rutz et al. 2014)] or extra-tropical cyclones [e.g., Agel et al. (2015)] embedded within upperlevel dynamics such as the jet stream (Pfahl and Wernli 2012) and cutoff upper-level low pressure systems (Abatzoglou 2016; Marquardt Collow et al. 2016). It is thus of interest to better understand the contribution of midlatitude circulation patterns to precipitation extremes on sub-daily timescales, and how this contribution varies geographically.

We focus here on two distinct midlatitude regimes, progressive disturbances embedded within the jet stream, and cutoff upper-level low pressure systems that are displaced equatorward from the jet stream. The jet stream is often associated with an underlying band of enhanced baroclinicity and instability and linked to midlatitude storm tracks, atmospheric rivers and extratropical wave cyclones (Strong and Davis 2008). Disturbances embedded within the jet stream are responsible for a large portion of the total seasonal precipitation in the winter (Hawcroft et al. 2012) and a majority of longer-duration extreme precipitation events along the west coast of the US (Pfahl and Wernli 2012), as seen on 6-7 Nov 2006 where an atmospheric river embedded within a jet stream event across the eastern Pacific ocean was responsible for setting up maximum 1-day precipitation accumulation exceeding $350 \mathrm{~mm}$ across parts of Washington and Oregon, contributing to historically record 1-day streamflow discharges for November (Neiman et al. 2008).

By contrast, cutoff lows (COL) occur when midlatitude wave energy extends equatorward of the jet during an amplified flow regime and ultimately become displaced from midlatitude flow [e.g., Nieto et al. (2007)]. Recent studies have shown that COL contribute to a substantial portion of annual precipitation and multi-day precipitation extremes across parts of the globe (Favre et al. 2013) including the US (Abatzoglou 2016). We can look to some well-known events where COL were partly responsible for extreme precipitation events on daily or even shorter timescales. These include Fayetteville, North Carolina on 29 September 2016, where a COL advected moisture from a tropical storm and was responsible for over $250 \mathrm{~mm}$ of precipitation in less than 24 hours, triggering severe flash flooding in some areas. Another example is Boulder, Colorado on 12 September 2013, where the absolute record of 1-day precipitation accumulation coincided with a COL. In view of these examples, it is of interest to quantify the contribution of these organized midlatitude systems to hourly precipitation extremes, given the importance of this timescale to storm impacts (Terti et al. 2017).

We examined the degree to which these two large-scale midlatitude synoptic patterns correspond with hourly precipitation extremes, acknowledging that the approach could be used on a richer taxonomy of synoptic patterns. We specifically focus on comparing and contrasting the contributions from progressive midlatitude waves embedded within the jet stream and COL seasonally and geographically across the US. This research question was addressed by pairing hourly precipitation observations across the conterminous US (CONUS) along with chronologies of locations of the jet stream and COL events from 1979-2011.

\section{Data and methods}

Hourly precipitation data (HPD) from $>6000$ stations in CONUS were acquired from 1979-2011 from the National Climatic Data Center. Quality control is a significant concern, especially when dealing with sub-daily measurements (Blenkinsop et al. 2017), hence all data classified as suspect using pre-existing flags were hereafter treated as missing [see Barbero et al. (2017) for further details]. A total of 416 stations that had at least 25 years of data missing no more than $20 \%$ of hourly data in any given year from 1979-2011 were used hereafter. We corrected for changes in the precision of precipitation measurement through time and space as this could introduce a bias in some of our statistics based on the mean duration of storms. We thus converted the data of the finer-resolution gauges to the uniform accuracy of $2.54 \mathrm{~mm}$ throughout the entire period of record following (Groisman et al. 2012).

We focus here on 1-h annual (Jan-Dec) maximum precipitation (AMP) and seasonal maximum precipitation (i.e. the maximum 1-h precipitation observed over DJF, MAM, JJA and SON). For example, the AMP at a specific location is defined as the maximum amount of precipitation falling during all hours of the year. This simple block maxima approach is often used in trend detection studies and in hydrology to produce estimates of return periods and the advantage is that AMP events are independent and identically distributed. Note that similar results were observed when considering maximum cumulative precipitation over any 1-, 3- or 6-h period. For conciseness, we only show results based on 1-h annual and seasonal maximum precipitation, regardless of the storm duration initiating such extremes.

Objective procedures were used to identify both the location of the jet stream and COL using reanalysis data from ERA-Interim (Dee et al. 2011). Rather than explicitly resolve midlatitude disturbances embedded within the jet stream, we followed (Koch et al. 2006) to define the location of the jet stream itself given that wave disturbances 
propagate along the jet. The horizontal wind speed was integrated over pressure surfaces from 100 to $400 \mathrm{hPa}$. Zonal and meridional wind components were acquired from Daily 0Z ERA-Interim at 0.75 resolution. A threshold criterion of wind speed exceeding $30 \mathrm{~m} \mathrm{~s}^{-1}$ was used to identify the presence of a jet stream following Koch et al. (2006). This definition is in general agreement with other studies Strong and Davis (2008) where the jet-core was defined as wind speed in upper-levels exceeding $25.7 \mathrm{~m} \mathrm{~s}^{-1}$.

We identified COL using the algorithm of Nieto et al. (2005) and Daily 0Z ERA-Interim data at 2.5 resolution. Per (Nieto et al. 2005), COL are identified as a local minima in $200 \mathrm{hPa}$ geopotential height (COL center) concomitant with easterly $200 \mathrm{hPa}$ flow immediately north of the height minima and a baroclinic zone immediately east of the height minima.

Hourly precipitation was identified as being part of a jet stream event for locations and hours within a distance of 660-km and \pm 1 -day of ERA-Interim upper-levels wind days exceeding $30 \mathrm{~m} \mathrm{~s}^{-1}$. Likewise, hourly precipitation within $660-\mathrm{km}$ of the centroid and within \pm 1 -day of the COL day was attributed to COL. This radius is consistent with previous studies pairing precipitation to midlatitude synoptic phenomenon (Porcù et al. 2007; Abatzoglou 2016). The padding by 1-day addresses potential differences in the transit time of a COL or a jet stream event [e.g., Oakley and Redmond (2014)]. The sensitivity of the results to the padding by 1-day was tested using shorter time windows. As expected, restricting the padding decreases the fraction of precipitation attributable to COL and jet stream events but results and overall conclusions were not substantially changed. Occasionally, hourly precipitation at a station could be associated with both COL and jet stream events. In this case, the COL category was given priority over the jet stream. As an illustration, Fig. 1 shows a cutoff low on June 12th 2010 centered on the western US that was responsible for setting up multiple 1-h AMP (red dots) on the same day in the Rocky Mountains. Likewise, Fig. 2 illustrates a jet stream event on 12 November 1981 extending across the entire Northern Pacific and setting up multiple 1-h AMP across the Pacific NW region, near the jet exit region. The number of days each station of the US were under the spatial window of influence of a jet stream or COL criteria was reported for each season of the year.

The percent of 1-h AMP attributed to the jet stream and COL was calculated separately for each station. We estimated the relative proportion of 1-h AMP concurrent with the jet stream and COL compared to the overall frequency of these synoptic regimes for each station. A resampling block procedure was used to test whether these synoptic regimes contribute disproportionately more than what we would expect with randomly chosen time series given their frequency. The resampling block procedure preserves serial correlation inherent with precipitation data and divides
Fig. 1 Example of a cutoff low (June 12th 2010) coinciding with 1-h AMP at 4 stations in the Rockies. Colors indicate the geopotential height at $200 \mathrm{hPa}$. Gray dots indicate hourly precipitation data (HPD) stations within the area of influence of the COL (black dashed circle) and red dots indicate HPD stations where 1-h AMP was observed on June 12th

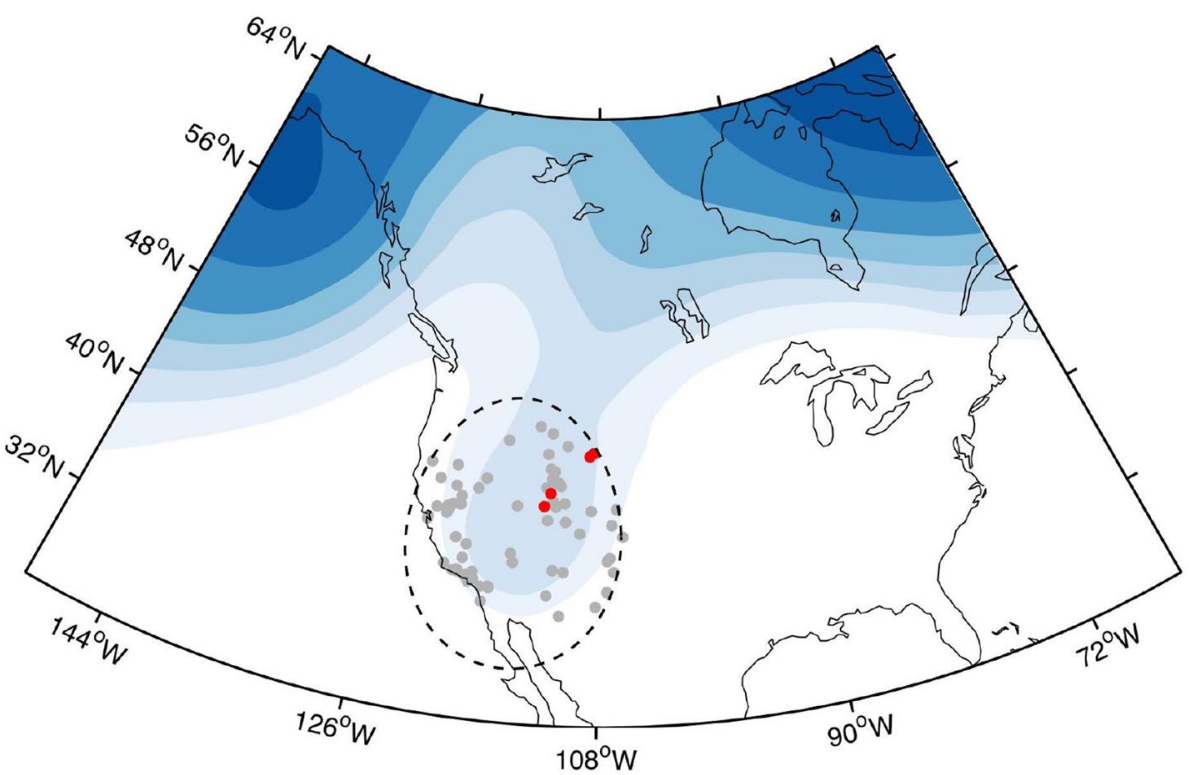

Geopotential height (200 hPa)

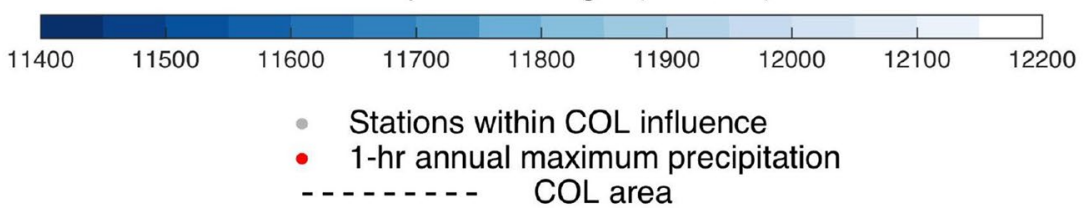




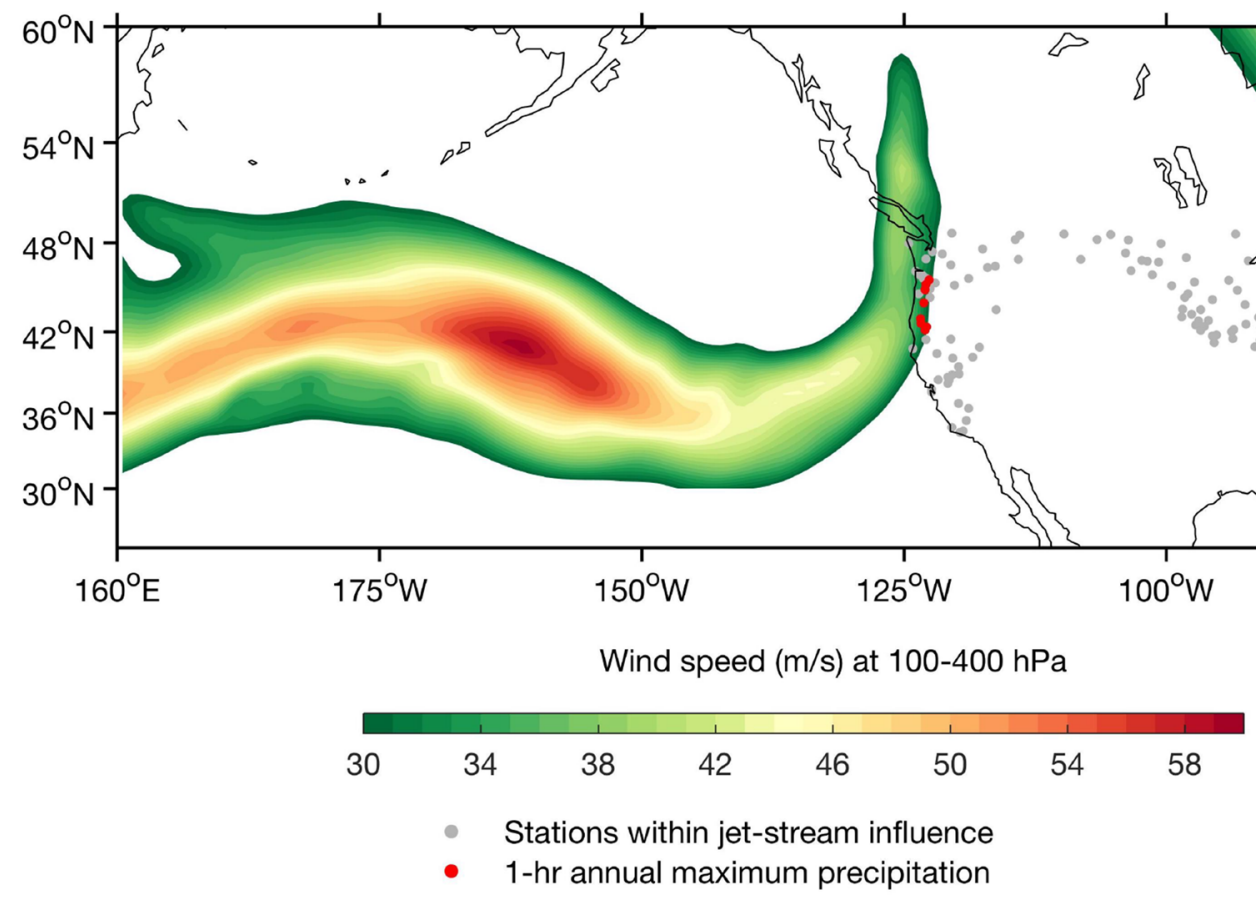

Fig. 2 Example of a jet stream event (12 November 1981) coinciding with 1-h AMP in the Pacific Northwest at seven HPD stations. Colors show wind speed at $100-400 \mathrm{hPa}$ (only values above $30 \mathrm{~m} \mathrm{~s}^{-1}$ are shown). Gray dots indicate HPD stations within the area of influ-

the data into non-overlapping blocks of 7 days, which are randomly reshuffled 100 times. We then computed the percent of randomly chosen 1-h AMP embedded within the jet stream or COL to obtain a statistical distribution of random matches between the jet stream or COL occurrence and 1-h AMP that occur purely by chance given the jet stream or COL frequency observed. This procedure preserves the number of days each station was exposed to a midlatitude synoptic feature as well as the temporal autocorrelation properties of the hourly precipitation time series. Results are considered statistically significant if the percentage of 1-h AMP embedded within the jet stream or COL exceeds the 95th percentile of the synthetic distributions.

1-h AMP may be embedded within long-duration storms (such as those usually associated with jet stream events or COL) or alternatively within short-duration storms (such as those associated with short-lived convective systems). The overall duration and cumulative precipitation of the storm during which the 1-h AMP occurred may have different impacts (Brommer et al. 2007). We illustrate geographic differences in storm characteristics by reporting on the mean intensity of 1-h AMP attributed to COL, jet-stream and others processes as well as the average duration and total precipitation depth of 1-h AMP producing storms. Statistics were reported only if more ence of the jet stream (grays dot in northern central US were under the influence of the jet stream either the day before or after November 12th) and red dots indicate HPD stations where 1-h AMP were observed on November 12th

than five 1-h AMP events belonging to a specific process were observed over the period of record. Storm duration was defined as the number of consecutive hours including the 1-h AMP during which no more than 6 consecutive dry hours occurred.

To better understand the seasonality of 1-h AMP across the contiguous US as well as the underlying 1-h AMPproducing mechanisms, we examined the percentage of 1-h AMP taking place within each season alongside relative contributions from the jet stream and COL.

Finally, we complement the climatological analysis by examining the large-scale dynamics associated with 1-h AMP using composite analysis. Specifically, composites were examined separately for 1-h AMP (1) embedded within the jet stream, (2) embedded within a COL and (3) all others. Composite maps of integrated water vapor flux (IWVF), total column water (TCW), geopotential height at $200 \mathrm{hPa}$ as well as convective available potential energy (CAPE) from ERA-Interim re-analyses were composited spatially relative to the location of individual stations, and temporally relative to the 1-h AMP date. We examined these composites using anomalies relative to the mean seasonal cycle to better identify perturbations relative to the background climatology. 
Cutoff low
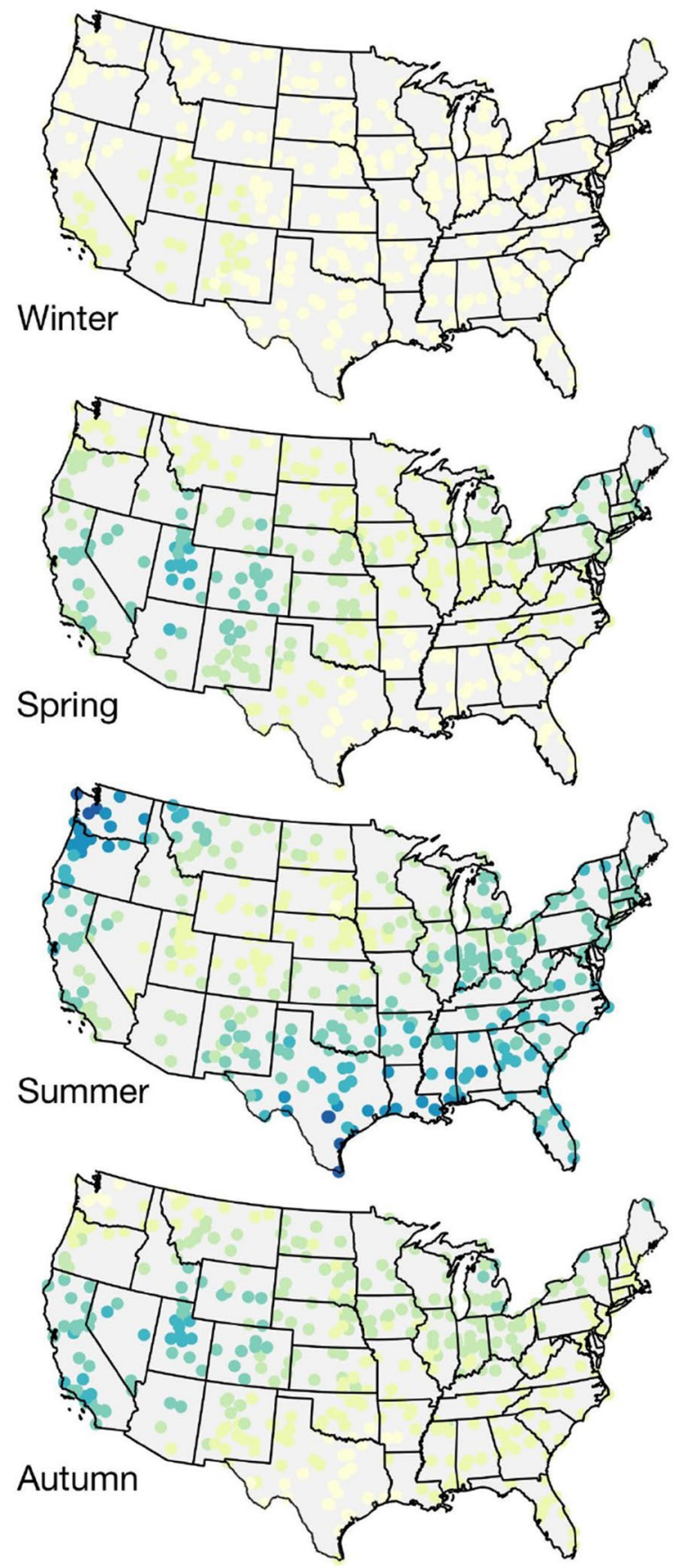

Jet-stream
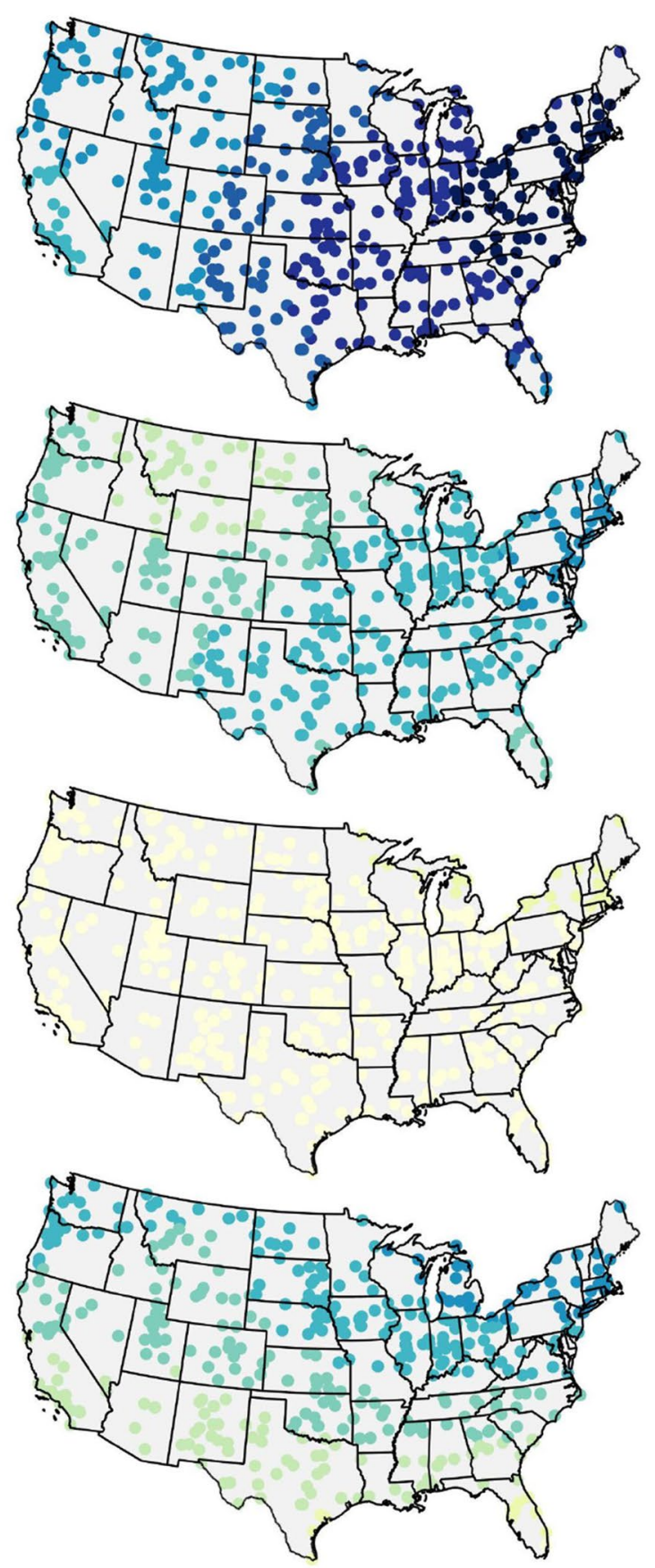

climatological \# of days within the spatial window of influence

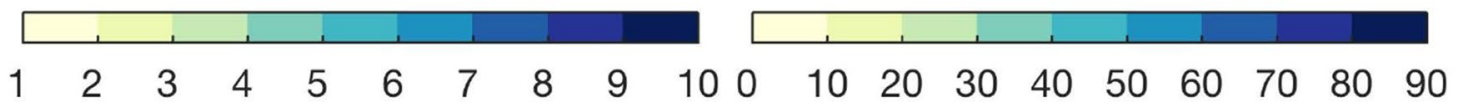

Fig. 3 Left: average number of days per season where HPD stations were within the spatial window of influence of cutoff lows. Right: same as left panel but for jet stream events. Note that color bars cover different ranges 


\section{Results}

The average number of days per season that stations were within the spatial window of influence of COL (i.e. within 660-km from a COL center) varied from less than two days in winter (DJF) across much of the US to over 10-days in summer (JJA) across the southern US (Fig. 3, left). Regional maxima in COL during spring (MAM) and autumn (SON) were found from California eastward to Colorado. These geographic and seasonal patterns for COL resemble those of Rossby wave breaking located downstream and southward of the jet exit region [e.g.,(Wernli and Sprenger 2007; Abatzoglou 2016)]. By contrast, the average number of days per season that stations were embedded within a jet stream event varied from nearly zero in the summer across the entire contiguous US to over 80 days in the winter across parts of eastern US (Fig. 3, right) when the planetary spiral-like structure of the jet stream is at its widest over Eastern US. This spatiotemporal pattern is consistent with previous findings (Koch et al. 2006) and is tied to the annual migration of baroclinicity latitudinally.

Cutoff lows contribution
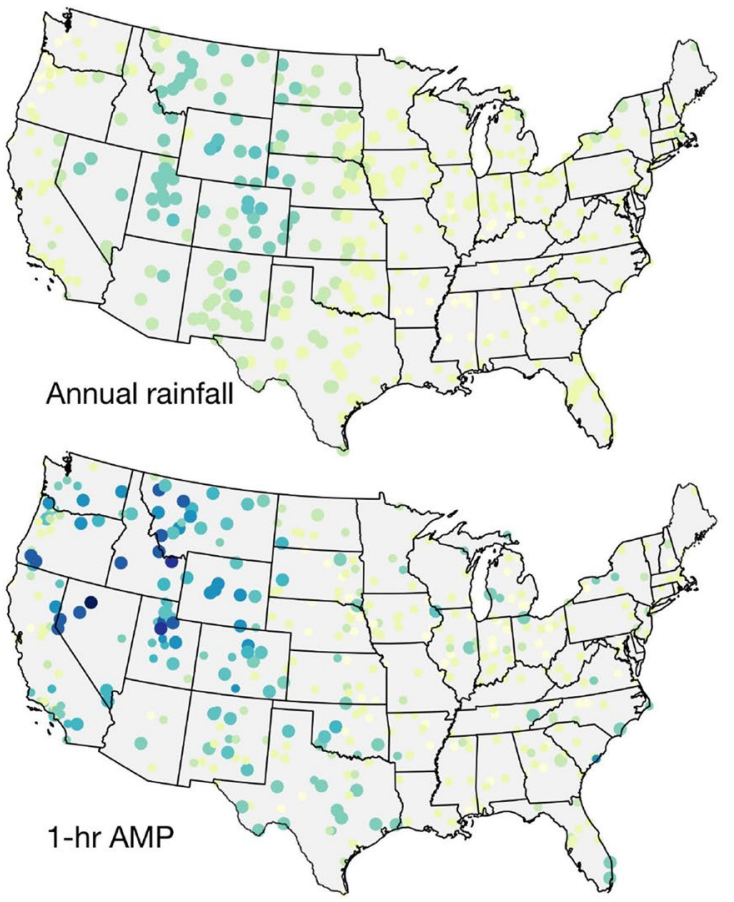

Percentage as cutoff low

$\begin{array}{lllllllllll}0 & 5 & 10 & 15 & 20 & 25 & 30 & 35 & 40 & 45 & 50\end{array}$

Fig. 4 Left: percent of annual precipitation and 1-h annual maximum precipitation (AMP) attributed to cutoff lows. Right: same as left panel but for jet stream events. Large circles indicate that COL or jet
While COL contribute to approximately $5-25 \%$ of annual precipitation at HPD stations across the interior western US, approximately $25-50 \%$ of 1-h AMP were coincident with COL (Fig. 4, left panel). This contribution exceeds what we would expect by chance given the COL frequency. While (Abatzoglou 2016) showed that a sizeable portion of multiday precipitation extremes were attributable to COL, we show here that COL contribute also substantially to precipitation extremes on sub-daily timescales. Nearly all 1-h AMP are associated with jet stream events along the western coastal states windward of the primarily north-south topographic barrier extending from the coast ranges in southern California, northward through the Sierra Nevada mountains and Cascades, while this contribution drops off in the interior western US (Fig. 4, right panel). Most of these extremes likely coincided with atmospheric rivers embedded with jet stream events that are known to be the primary feature that causes flooding across the region (Konrad and Dettinger 2017). Jet stream events are also responsible for $50-70 \%$ of annual precipitation over a region extending from the Ohio River Valley into the southeastern US. However, the

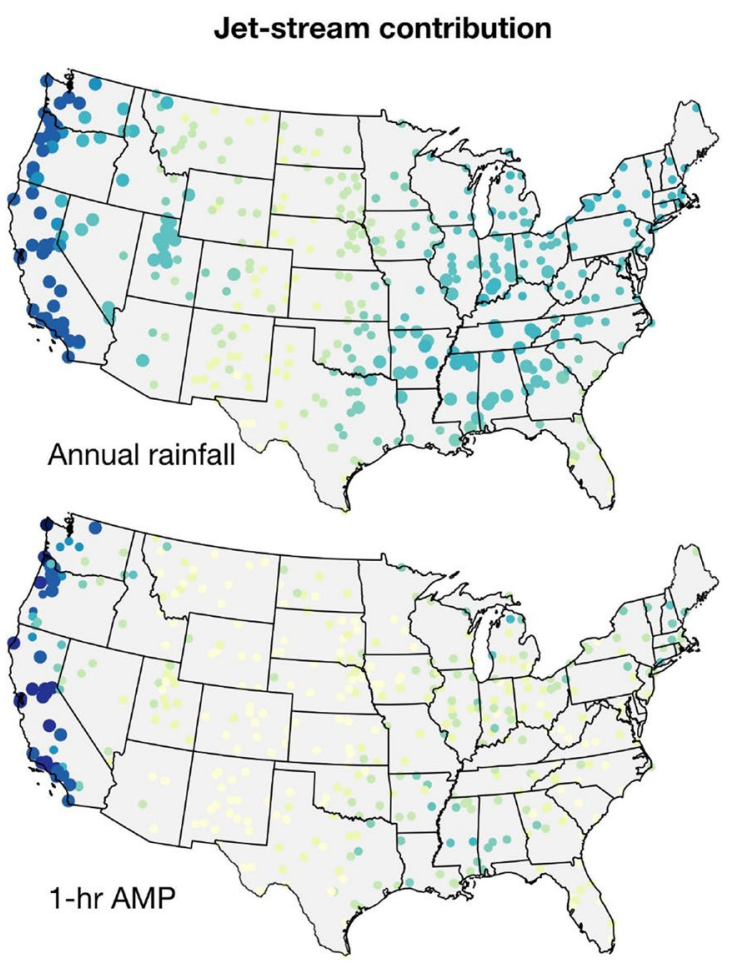

Percentage as jet stream

$0 \quad 1020 \quad 304050 \quad 6070 \quad 8090 \quad 100$

stream contribution is statistically significant at the $95 \%$ confidence level according to a resampling based-procedure. Note that color bars cover different ranges 
contribution to 1-h AMP is weaker and falls within the confidence range and is thus proportionate to the jet stream frequency. In the rest of the US, the jet stream contribution to 1-h AMP is nominal as precipitation extremes in these areas are generally set when other extra-tropical frontal systems (Marquardt Collow et al. 2016), tropical cyclones (Knight and Davis 2009; Kunkel et al. 2010), meso-scale convective systems (Kunkel et al. 2012) or purely localized convective processes transit over the region.

It is readily apparent that the mean intensity of $1-\mathrm{h}$ AMP depends more on the geographic location than it does on the triggering atmospheric mechanism (Fig. 5, left panel), with the largest intensities found in the Southeastern US where the combined effect of moisture availability and the moisture holding capacity of the atmosphere gives rise to the most intense hourly precipitation rates. As expected, 1-h AMP tied to jet stream events are embedded within longer-duration storms, lasting on average 6-12 hours in the east coast and $>24 \mathrm{~h}$ along the US west coast (Fig. 5, right panel). The longest COL storms producing 1-h AMP events were found near the eastern slopes of the Rocky Mountains. Finally, the largest total precipitation accumulations coincident with 1-h AMP producing storms were generally initiated by jet stream events but also by other systems in the eastern half of the US.

Figure 6 shows the seasonality of 1-h AMP alongside the seasonal contribution of COL and jet stream. Neither COL or jet stream events were significant contributors to 1-h AMP that occurred predominantly during the summer in the eastern two-thirds of the US. By contrast, the jet stream was as a major contributor to 1-h AMP occurring during winter along the Pacific coast when the jet stream and moisture flux are perpendicular to the coastal mountain ranges and contribute to the orographic precipitation enhancement. COL contributed to a certain extent to 1-h AMP in spring and fall across parts of the Rocky Mountains and the Great Basin.

When restricting the analysis to the 1-h seasonal maximum precipitation, COL contributed more than $60 \%$ of $1-\mathrm{h}$ spring maximum precipitation across parts of the western US (with the highest contribution in the Southern Rockies) and more than $50 \%$ of fall 1-h maximum precipitation in the central Rockies (Fig. 7, left panel). The impacts of these precipitation extremes include exacerbating runoff during times of the year when soil moisture is saturated and snowmelt occurs (Berghuijs et al. 2016; Villarini 2016), as well as triggering flash floods (Gochis et al. 2015). Likewise, nearly all winter 1 -h maximum precipitation are associated
Fig. 5 Left: mean intensity of 1-h annual maximum precipitation (AMP) attributed to cutoff lows, jet-stream and others processes. Note the non-linear color bar. Right: average duration (shading) and average precipitation depth (circle size) of 1-h AMP producing storms. In this case, stations were discarded if less than five 1-h AMP events belonging to a specific process were observed over the period of record

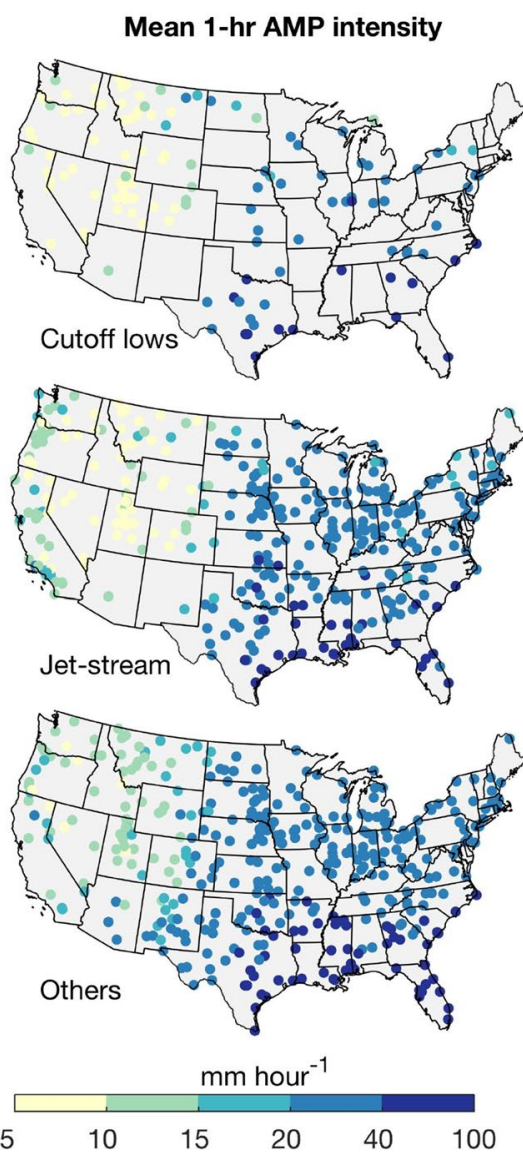

Mean duration 1-hr AMP producing storms
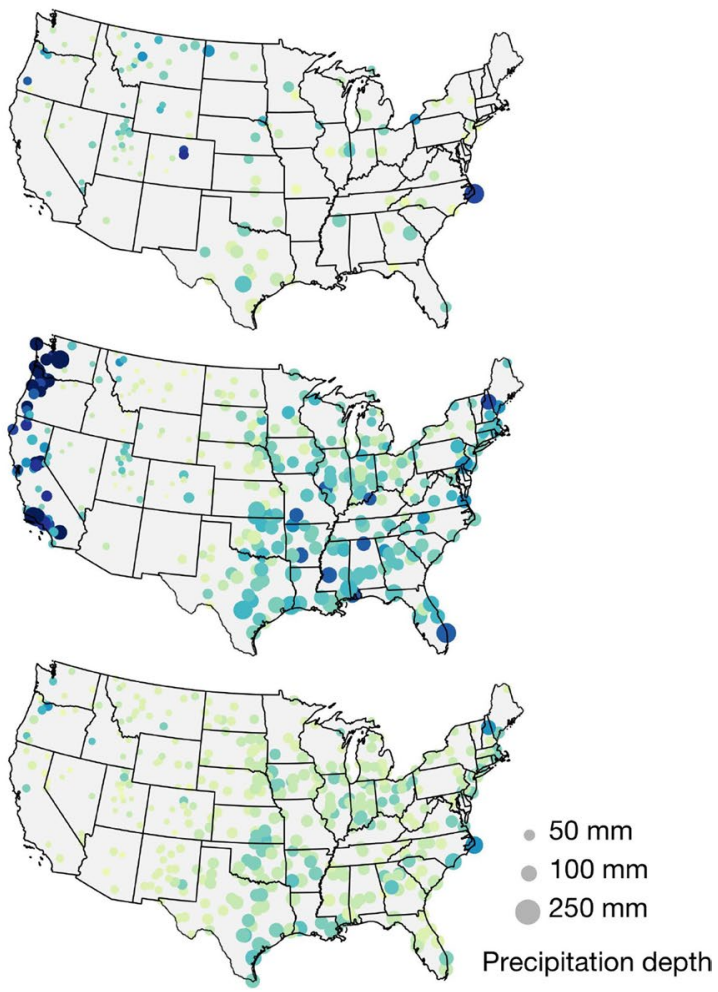

duration (hours)

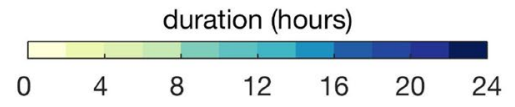




\section{(a) Winter}
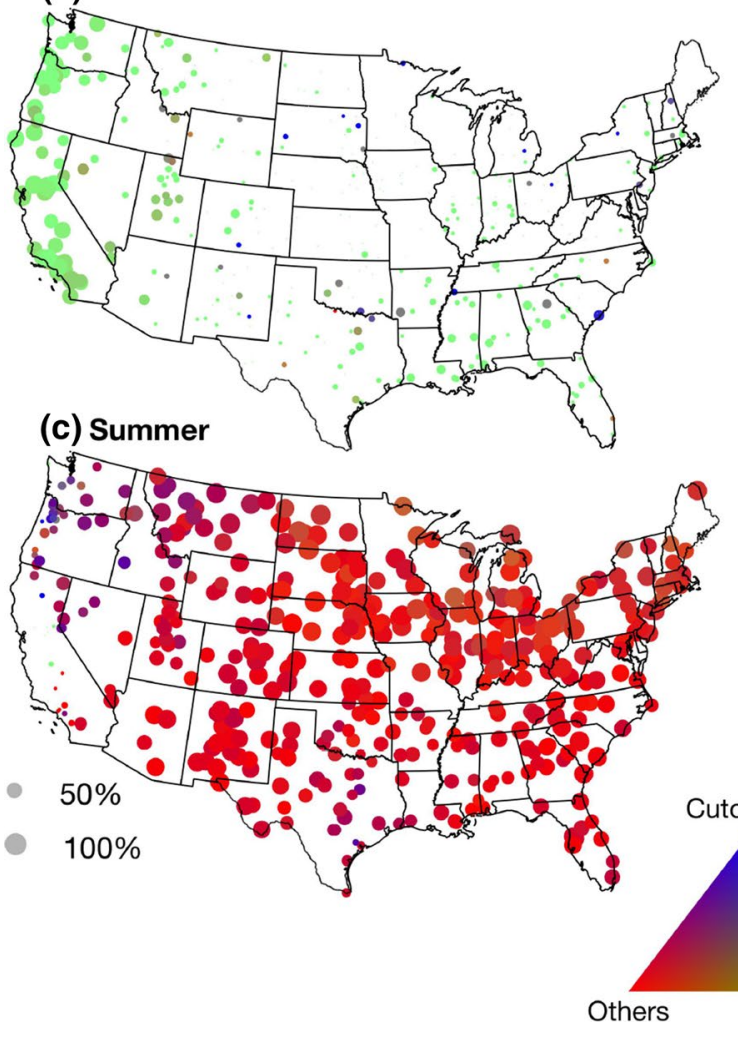

Fig. 6 Relative proportion of 1-h annual maximum precipitation (AMP) that occurred in a winter, b spring, $\mathbf{c}$ summer, $\mathbf{d}$ autumn and associated typology. The area of each symbol shows the relative proportion occurring in each season. The color of each symbol shows the

\section{(b) Spring}
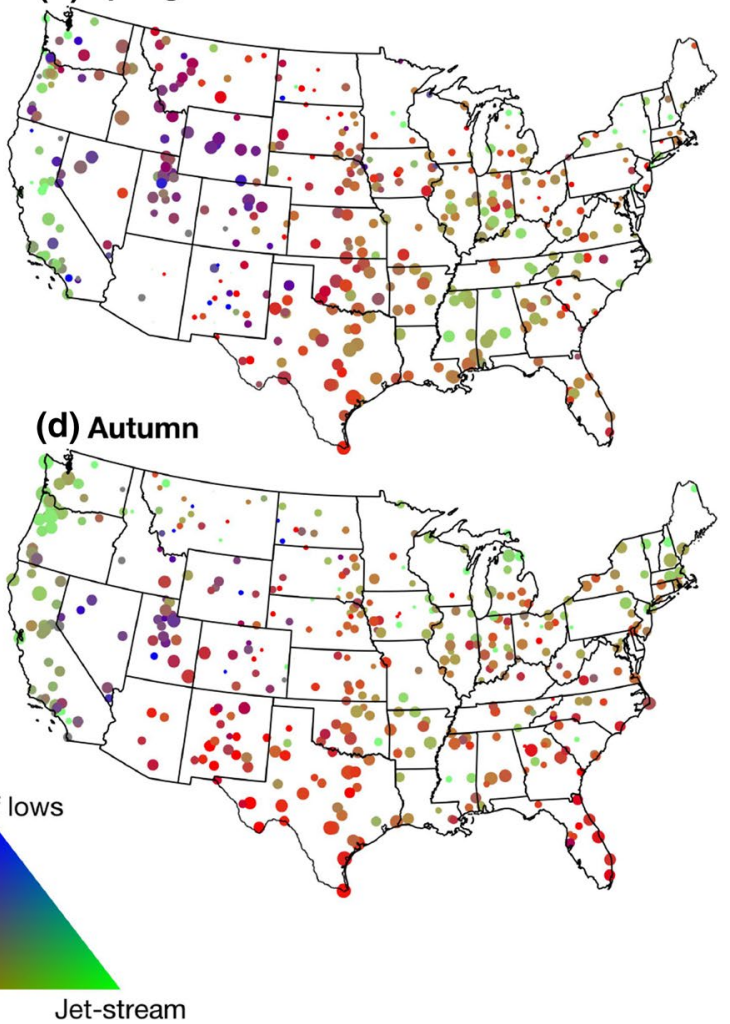

relative distribution of typologies for 1-h AMP for that season. The typology is indicated by the 2-dimensional color scale (cutoff lows in blue, jet stream events in green and other systems in red) such that the sum over all types equals $100 \%$

with jet stream events across the US (Fig. 7, right panel), and can contribute to flooding especially in coastal mountain watersheds along the Pacific (Lamjiri et al. 2017; Ralph et al. 2006) or in the eastern US when rainfall exceeds the soil moisture storage capacity (Berghuijs et al. 2016). The jet stream also contributed to over $60 \%$ of spring and fall 1-h maximum precipitation in the eastern third of the US, although this contribution was expected given the jet stream frequency.

Finally, we examine composites of TCW, IWVF, 200$\mathrm{hPa}$ geopotential height and CAPE anomaly fields to better understand the role of atmospheric dynamics and moisture advection in the occurrence of 1-h AMP associated with COL, with jet stream events and those not associated with either of these synoptic features. The COL composite (Fig. 8, top-left) shows a strong anomalous northward moisture flux and elevated TCW east of the station with a closed upper-level cyclonic anomaly to the west such that the station is generally positioned where the temperature frontal gradient is the highest (Catto and Pfahl 2013). By contrast, 1-h AMP coincident with jet stream events are fed by a strong east-northeastward moisture flux along the southern flank of the cyclonic anomaly (Fig. 8, topmiddle) with the upper-level trough northwest of the station. Composites for 1-h AMP not associated with COL or jet-stream events showed relatively weak $200-\mathrm{hPa}$ flow anomalies, which is likely due to the pooling of multiple processes including meso-scale convective systems, frontal systems, tropical cyclones and localized air mass convection, although there is evidence to suggest that the cyclonic-anticyclonic couplet enables a strong northward IWVF and elevated TCW collocated with the station (Fig. 8, top-right).

Figure 8 (bottom) shows positive CAPE anomalies centered on the station for all 1-h AMP, confirming (1) the role of atmospheric stability parameters in the occurrence of hourly rainfall accumulation extremes (Lepore et al. 2015) and (2) that large-scale dynamical features such as COL or jet streams may also promote instability. Enhanced CAPE observed during 1-h AMP not associated with midlatitude dynamics is probably associated with surface heating and elevated levels of TCW whereas that for COL-related 1-h AMP was probably associated with anomalous cold air in the mid-to-upper troposphere that helps to destabilize the 


\section{Cutoff low contribution}
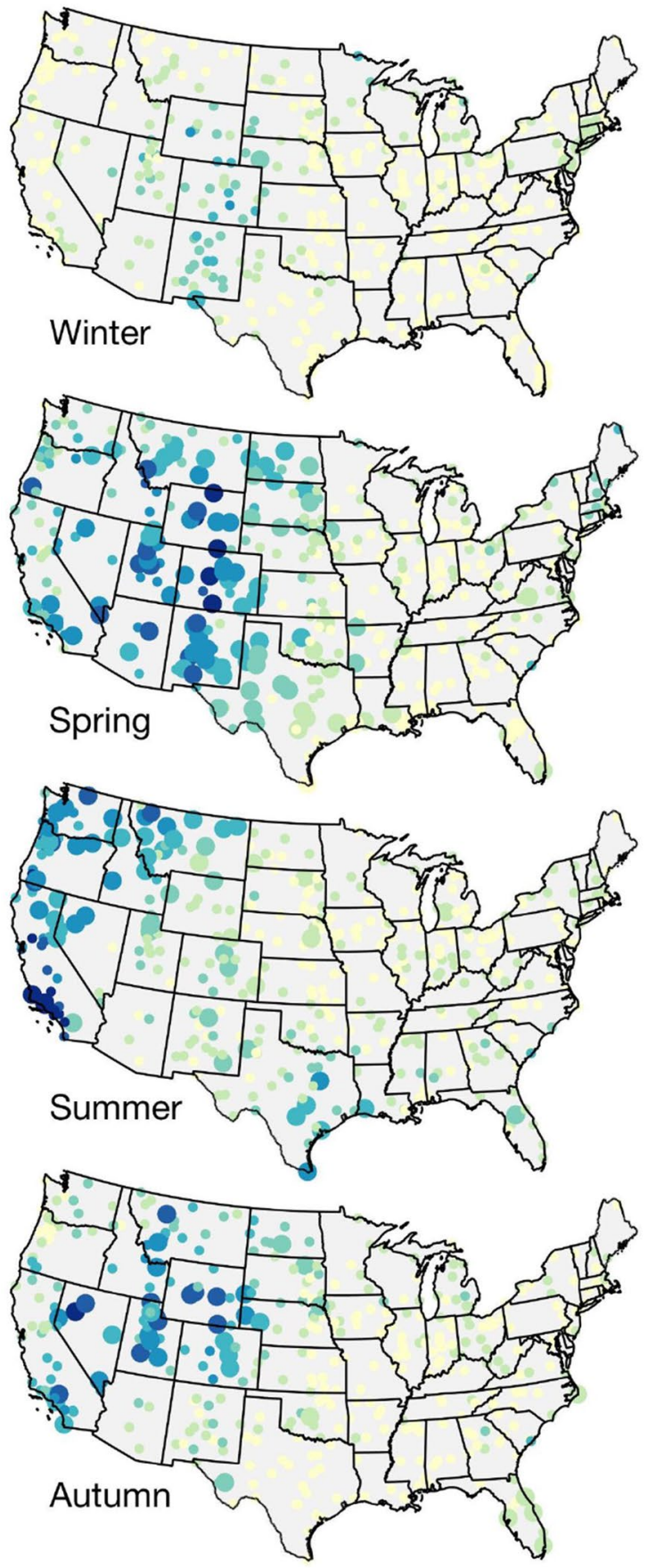

Percentage as cutoff low

$\begin{array}{llllllll}0 & 10 & 20 & 30 & 40 & 50 & 60 & 70\end{array}$

Fig. 7 Left: percent of the 1-h seasonal maximum precipitation attributed to cutoff lows. Right: same as left panel but for jet stream events. Large circles indicate that cutoff lows or jet stream contribution is sta-
Jet-stream contribution
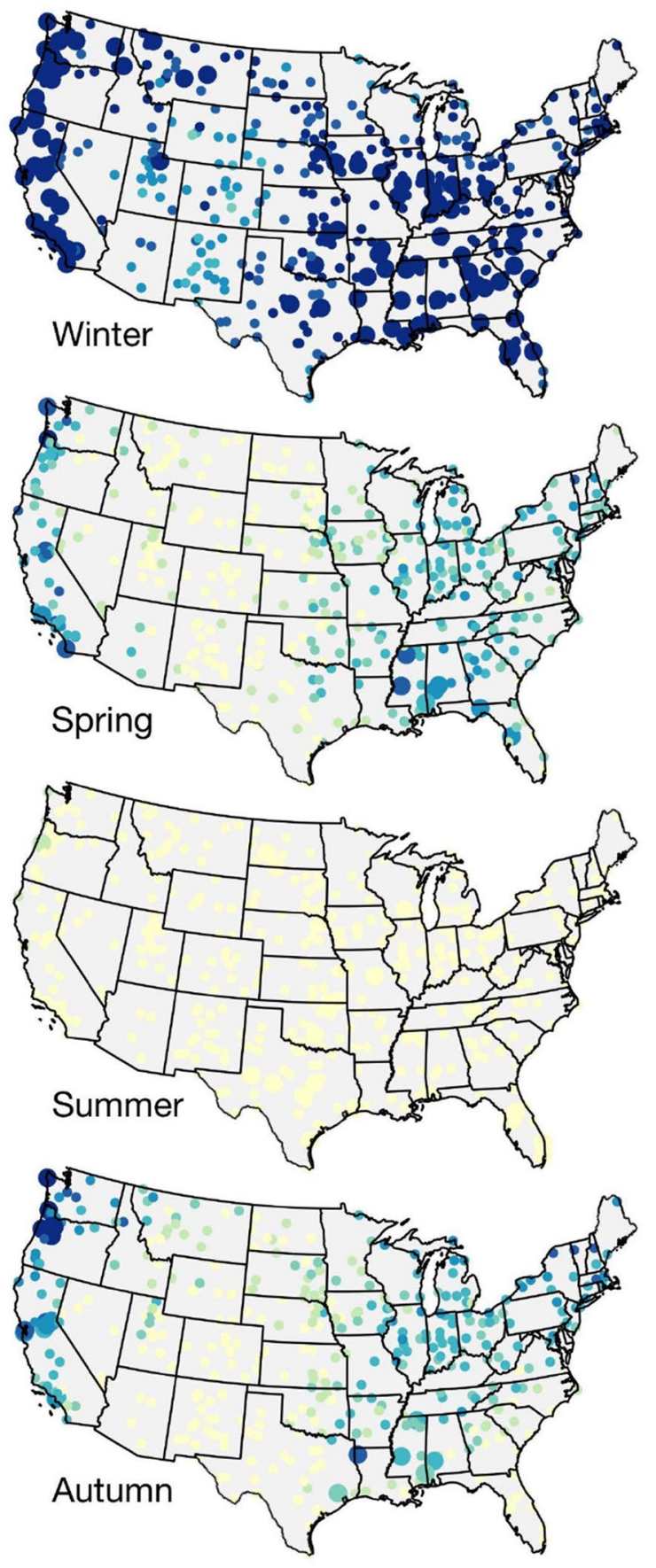

Percentage as jet stream

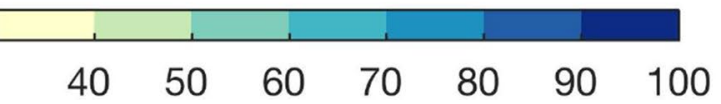

tistically significant at the $95 \%$ confidence level according to a resampling based-procedure. Note that color bars cover different ranges 

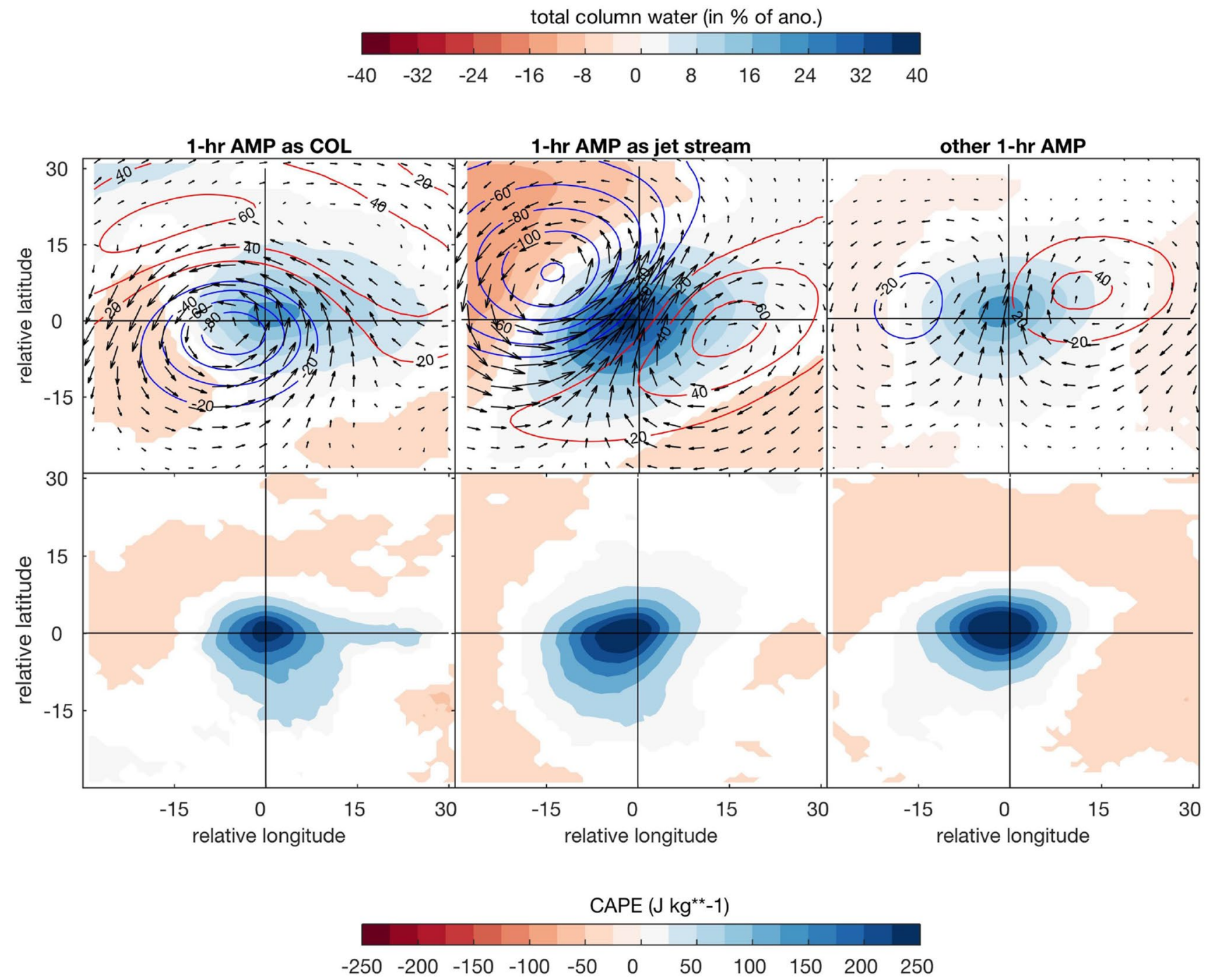

Fig. 8 Top: composites of total column water (TCW) as \% of anomalies relative to the mean seasonal cycle (shaded), geopotential height anomalies at $200 \mathrm{hPa}$ (contour with red and blue isolines representing positive and negative anomalies respectively) and integrated water vapor flux (IWVF) anomalies (vectors, largest vector shown is 187.5 $\mathrm{kg} \mathrm{m}^{-1} \mathrm{~s}^{-1}$ ) associated with 1-h annual maximum (AMP) days as cutoff lows (left), jet stream (middle) and all other events (right). Bot-

atmosphere (Singleton and Reason 2007). Collectively, these results show that midlatitude dynamics facilitate anomalous moisture advection and large-scale upward motion.

\section{Concluding remarks}

We demonstrated that midlatitude dynamics contribute to a large portion of hourly rainfall accumulation extremes across portions of the US. Overall, we found that both COL and jet stream disturbances disproportionately contribute to the occurrence of hourly rainfall accumulation extremes tom: same as top panel but for convective available potential energy (CAPE). Only values significantly different from zero $(\mathrm{p}<0.05)$ are shown (zonal or meridional component of IWVF). Each field has been relocated relative to station location (coordinates: 0,0 ) such that the center of the map corresponds to the location of each 1-h AMP. Note that the same storm was composited $N$ times if it caused 1-h AMP at $N$ stations

relative to their overall frequency across the western US. The jet stream was found to be a major driver of hourly rainfall accumulation extremes along the west coast and to a lesser extent across parts of the Ohio River Valley and the southeastern US, complementing work by previous studies for longer duration precipitation extremes (Ralph and Dettinger 2012). COL were found to be responsible for a considerable portion of hourly rainfall accumulation extremes in the shoulder seasons across the interior western US, complementing previous studies for longer-duration extremes (Abatzoglou 2016). By contrast, purely convective precipitation, meso-scale convective systems, tropical cyclones or 
other midlatitude dynamics not examined in this study are likely the major contributors of hourly rainfall accumulation extremes in the eastern US, highlighting differences between storm mechanisms producing hourly rainfall accumulation extremes across the US.

We stress that multiple definitions of the jet stream and COL have been proposed in the literature and their use may yield slightly different contributions to hourly rainfall accumulation extremes. For example, the jet stream was defined solely on wind speed without inclusion of frontogenesis or cyclones in the definition. The criteria for detecting the jet stream may also be too stringent in the summer.

Further studies based on streamflow data or reports of flash-flooding may better elucidate the impact of midlatitude disturbances on flooding at sub-daily scales. For instance, the combination of snowmelt in the spring with cutoff low occurrences in the interior western US may be responsible for flooding events and related impacts such as erosion.

Finally, more research is required to better disentangle the contributions of large-scale circulation from small-scale convective processes at hourly scales to better understand future changes to hourly rainfall accumulation extremes. While convection-permitting models simulate an intensification of extreme precipitation rates over the United States due to strictly thermodynamic factors (Prein et al. 2016), changes in dynamics such as an intensification and poleward shift of the jet stream (Pfahl et al. 2017; Yin 2005) may regionally amplify or weaken the thermodynamical response of precipitation extremes. Despite these projected dynamical changes, for hourly extremes limited convection-permitting model studies over different regions find robust increases in intensities with warming (Kendon et al. 2017).

Acknowledgements The authors appreciate the constructive reviews by three anonymous reviewers who helped improve the quality of this manuscript. This work was supported by the INTENSE project. INTENSE is supported by the European Research Council (Grant ERC2013-CoG-617329). Hayley Fowler is funded by the Wolfson Foundation and the Royal Society as a Royal Society Wolfson Research Merit Award holder (grant WM140025). The hourly precipitation data was acquired from the National Climatic Data Center at http://www1.ncdc. noaa.gov/pub/data/hourly_precip-3240/. Era-interim data was acquired from the ECMWF website at https://www.ecmwf.int/en/research/clima te-reanalysis/era-interim.

Open Access This article is distributed under the terms of the Creative Commons Attribution 4.0 International License (http://creativeco mmons.org/licenses/by/4.0/), which permits unrestricted use, distribution, and reproduction in any medium, provided you give appropriate credit to the original author(s) and the source, provide a link to the Creative Commons license, and indicate if changes were made.

\section{References}

Abatzoglou JT (2016) Contribution of cutoff lows to precipitation across the United States*. J Appl Meteorol Climatol 55(4):893. https://doi.org/10.1175/JAMC-D-15-0255.1

Agel L, Barlow M, Qian JH, Colby F, Douglas E, Eichler T (2015) Climatology of daily precipitation and extreme precipitation events in the Northeast United States. J Hydrometeorol 16(6):2537. https ://doi.org/10.1175/JHM-D-14-0147.1

Ashley ST, Ashley WS (2008) Flood fatalities in the United States. J Appl Meteorol Climatol. https://doi.org/10.1175/2007JAMC16 11.1

Barbero R, Fowler H, Lenderink G, Blenkinsop S (2017) Is the intensification of precipitation extremes with global warming better detected at hourly than daily resolutions? Geophys Res Lett 44(2) https://doi.org/10.1002/2016GL071917

Berghuijs WR, Woods RA, Hutton CJ, Sivapalan M (2016) Dominant flood generating mechanisms across the United States. Geophys Res Lett 43(9):4382. https://doi.org/10.1002/2016GL068070

Blenkinsop S, Lewis E, Chan SC, Fowler HJ (2017) Quality-control of an hourly rainfall dataset and climatology of extremes for the UK. Int J Climatol 37(2):722. https://doi.org/10.1002/joc.4735

Brommer DM, Cerveny RS, Balling RC (2007) Characteristics of longduration precipitation events across the United States. Geophys Res Lett 34(22):2. https://doi.org/10.1029/2007GL031808

Catto JL, Pfahl S (2013) The importance of fronts for extreme precipitation. J Geophys Res Atmos 118(19):10791. https://doi. org/10.1002/jgrd.50852

Dee D, Uppala S, Simmons a, Berrisford P, Poli P, Kobayashi S, Andrae U, Balmaseda M, Balsamo G, Bauer P (2011) The ERA—interim reanalysis: configuration and performance of the data assimilation system. Quat J R Meteorol Soc. https://doi.org/10.1002/qj.828

Dettinger MD, Ralph FM, Das T, Neiman PJ, Cayan DR (2011) Atmospheric rivers, floods and the water resources of California. Water. https://doi.org/10.3390/w3020445

Dwyer JG, O'Gorman PA (2017) Changing duration and spatial extent of midlatitude precipitation extremes across different climates. Geophys Res Lett 44(11):5863. https://doi.org/10.1002/2017G L072855

Favre A, Hewitson B, Lennard C, Cerezo-Mota R, Tadross M (2013) Cut-off Lows in the South Africa region and their contribution to precipitation. Clim Dyn 41(9-10):2331. https://doi.org/10.1007/ s00382-012-1579-6

Gochis D, Schumacher R, Friedrich K, Doesken N, Kelsch M, Sun J, Ikeda K, Lindsey D, Wood A, Dolan B, Matrosov S, Newman A, Mahoney K, Rutledge S, Johnson R, Kucera P, Kennedy P, Sempere-Torres D, Steiner M, Roberts R, Wilson J, Yu W, Chandrasekar V, Rasmussen R, Anderson A, Brown B (2015) The great Colorado flood of September 2013. Bull Am Meteorol Soc 96(9):1461. https://doi.org/10.1175/BAMS-D-13-00241.1

Groisman PY, Knight RW, Karl TR (2012) Changes in intense precipitation over the central United States. J Hydrometeorol 13(1):47. https://doi.org/10.1175/JHM-D-11-039.1

Hawcroft MK, Shaffrey LC, Hodges KI, Dacre HF (2012) How much Northern Hemisphere precipitation is associated with extratropical cyclones? Geophys Res Lett 39(24):1. https://doi. org/10.1029/2012GL053866

Kendon EJ, Ban N, Roberts NM, Fowler HJ, Roberts MJ, Chan SC, Evans JP, Fosser G, Wilkinson JM (2017) Do convection-permitting regional climate models improve projections of future precipitation change? Bull Am Meteorol Soc. https://doi.org/10.1175/ BAMS-D-15-0004.1

Knight DB, Davis RE (2009) Contribution of tropical cyclones to extreme rainfall events in the southeastern United States. J 
Geophys Res Atmos 114(23):1. https://doi.org/10.1029/2009J D012511

Koch P, Wernli H, Davies HC (2006) An event-based jet-stream climatology and typology. Int J Climatol 26(3):283. https://doi. org/10.1002/joc. 1255

Konrad CP, Dettinger MD (2017) Flood runoff in relation to water vapor transport by atmospheric rivers over the Western United States, 1949-2015. Geophys Res Let 44(22):11456-11462. https ://doi.org/10.1002/2017GL075399

Kunkel KE, Easterling DR, Kristovich DAR, Gleason B, Stoecker L, Smith R (2010) Recent increases in U.S. heavy precipitation associated with tropical cyclones. Geophys Res Lett 37(24):2. https:// doi.org/10.1029/2010GL045164

Kunkel KE, Easterling DR, Kristovich DAR, Gleason B, Stoecker L, Smith R (2012) Meteorological causes of the secular variations in observed extreme precipitation events for the conterminous United States. J Hydrometeorol 13(3):1131. https://doi. org/10.1175/JHM-D-11-0108.1

Lamjiri MA, Dettinger MD, Ralph FM, Guan B (2017) Hourly storm characteristics along the U.S. West Coast: role of atmospheric rivers in extreme precipitation. Geophysical Res Lett 44(13):7020. https://doi.org/10.1002/2017GL074193

Lenderink G, Barbero R, Loriaux J, Fowler H (2017) Super-Clausius-Clapeyron scaling of extreme hourly convective precipitation and its relation to large-scale atmospheric conditions. J Clim 30(15). https://doi.org/10.1175/JCLI-D-16-0808.1

Lepore C, Veneziano D, Molini A (2015) Temperature and CAPE dependence of rainfall extremes in the eastern United States. Geophys Res Lett 42(1):74. https://doi.org/10.1002/2014GL062247

Loriaux JM, Lenderink G, Siebesma A Pier (2017) Large-scale controls on extreme precipitation. J Clim 30(3):955. https://doi. org/10.1175/JCLI-D-16-0381.1

Marquardt Collow AB, Bosilovich MG, Koster RD (2016) Large-Scale Influences on Summertime Extreme Precipitation in the Northeastern United States. J Hydrometeorol. https://doi.org/10.1175/ JHM-D-16-0091.1

Neiman PJ, Ralph FM, Wick GA, Kuo YH, Wee TK, Ma Z, Taylor GH, Dettinger MD (2008) Diagnosis of an intense atmospheric river impacting the Pacific Northwest: storm summary and offshore vertical structure observed with cosmic satellite retrievals. Mon Weather Rev 136(11):4398. https://doi.org/10.1175/2008M WR2550.1

Nieto R, Gimeno L, De la Torre L, Ribera P, Barriopedro D, GarcíaHerrera R, Serrano A, Gordillo A, Redaño A, Lorente J (2007) Interannual variability of cut-off low systems over the European sector: The role of blocking and the Northern Hemisphere circulation modes. Meteorol Atmos Phys. https://doi.org/10.1007/s0070 3-006-0222-7

Nieto R, Gimeno L, de la Torre L, Ribera P, Gallego D, García-Herrera R, García JA, Nuñez M, Redaño A, Lorente J (2005) Climatological features of cutoff low systems in the Northern Hemisphere. J Clim. https://doi.org/10.1175/JCLI3386.1

Oakley NS, Redmond KT (2014) A Climatology of 500-hPa closed lows in the northeastern pacific ocean, 1948-2011. J Appl Meteorol Climatol. https://doi.org/10.1175/JAMC-D-13-0223.1

Pall P, Allen MR, Stone DA (2007) Testing the Clausius-Clapeyron constraint on changes in extreme precipitation under $\mathrm{CO}_{2}$ warming. Clim Dyn 28(4):351. https://doi.org/10.1007/s0038 2-006-0180-2

Pfahl S, OGorman PA, Fischer EM (2017) Understanding the regional pattern of projected future changes in extreme precipitation, Nat Clim Change 7(6):423. https://doi.org/10.1038/nclimate3287
Pfahl S, Wernli H (2012) Quantifying the relevance of cyclones for precipitation extremes. J Clim 25(19):6770. https://doi.org/10.1175/ JCLI-D-11-00705.1

Porcù F, Carrassi A, Medaglia CM, Prodi F, Mugnai A (2007) A study on cut-off low vertical structure and precipitation in the Mediterranean region. Meteorol Atmos Phys. https://doi.org/10.1007/ s00703-006-0224-5

Prein AF, Rasmussen RM, Ikeda K, Liu C, Clark MP, Holland GJ (2016) The future intensification of hourly precipitation extremes. Nat Clim Change 7(1):48. https://doi.org/10.1038/nclimate3168

Prein AF, Liu C, Ikeda K, Trier SB, Rasmussen RM, Holland GJ, Clark MP (2017) Increased rainfall volume from future convective storms in the US. Nat Clim Change, pp 1-7. https://doi. org/10.1038/s41558-017-0007-7

Ralph FM, Dettinger MD (2012) Historical and national perspectives on extreme west coast precipitation associated with atmospheric rivers during december 2010. Bull Am Meteorol Soc 93(6):783. https://doi.org/10.1175/BAMS-D-11-00188.1

Ralph FM, Neiman PJ, Wick GA, Gutman SI, Dettinger MD, Cayan DR, White AB (2006) Flooding on California's Russian River: Role of atmospheric rivers. Geophys Res Lett. https://doi. org/10.1029/2006GL026689

Rutz JJ, Steenburgh WJ, Ralph FM (2014) Climatological characteristics of atmospheric rivers and their inland penetration over the Western United States. Mon Weather Rev 142(2):905. https://doi. org/10.1175/MWR-D-13-00168.1

Schumacher R, Johnson R (2006) Characteristics of U.S. extreme rain events during 1999-2003. Weather Forecast. https://doi. org/10.1175/WAF900.1

Singleton AT, Reason CJC (2007) A numerical model study of an intense cutoff low pressure system over South Africa. Mon Weather Rev. https://doi.org/10.1175/MWR3311.1

Strong C, Davis RE (2008) Variability in the position and strength of winter jet stream cores related to northern hemisphere teleconnections. J Clim. https://doi.org/10.1175/2007JCLI1723.1

Terti G, Ruin I, Anquetin S, Gourley JJ (2017) A situation-based analysis of flash flood fatalities in the United States. Bull Am Meteorol Soc 98(2):333. https://doi.org/10.1175/BAMS-D-15-00276.1

Utsumi N, Kim H, Kanae S, Oki T (2017) Relative contributions of weather systems to mean and extreme global precipitation. J Geophys Res: Atmos 122(1):152. https://doi.org/10.1002/2016J D025222

Villarini G (2016) On the seasonality of flooding across the continental United States. Adv Water Resour 87:80. https://doi.org/10.1016/j. advwatres.2015.11.009

Wernli H, Sprenger M (2007) Identification and ERA-15 Climatology of Potential Vorticity Streamers and Cutoffs near the Extratropical Tropopause. J Atmos Sci. https://doi.org/10.1175/JAS3912.1

Yin JH (2005) A consistent poleward shift of the storm tracks in simulations of 21st century climate. Geophys Res Lett 32(18):1. https ://doi.org/10.1029/2005GL023684

Zhang W, Villarini G, Scoccimarro E, Vecchi GA (2017) Stronger influences of increased $\mathrm{CO}_{2}$ on subdaily precipitation extremes than at the daily scale. Geophys Res Lett 44(14):7464. https://doi. org/10.1002/2017GL074024

Zhao S, Deng Y, Black RX, Zhao S, Deng Y, Black RX (2016) A dynamical and statistical characterization of United States extreme precipitation events and their associated large-scale meteorological patterns. J Clim. https://doi.org/10.1175/JCLI-D-15-0910.1 